\title{
O REPUBLICANISMO DE TOCQUEVILLE COMO CRÍTÍCA AO DESPOTISMO NAS ERAS DEMOCRÁTICAS
}

\author{
Tocqueville's republicanism as a critique to despotism in democratic eras
}

\author{
Juliano Cordeiro da Costa Oliveira \\ UFPI/PNPD
}

\begin{abstract}
Resumo: O objetivo deste artigo é investigar o republicanismo presente no pensamento de Alexis de Tocqueville, como crítica ao despotismo nas eras democráticas. Para tanto, seguiremos a leitura interpretativa de autores contemporâneos como Hannah Arendt, Charles Taylor e Jacques Rancière, que destacam, em suas reflexões, a interpretação de Tocqueville acerca da revolução americana, enfatizando os limites e as possibilidade de uma política participativa como crítica a um despotismo emergente na democracia. Tocqueville observa uma tendência, na democracia, de um crescente individualismo modemo, junto com a perda dos laços comunitários, essenciais para a vida pública. Ele mostra-se preocupado com a indiferença pela política enquanto participação da sociedade nas decisões, havendo o perigo de uma nova, especificamente moderna, forma de despotismo. Não será uma tirania do terror e da opressão. O governo poderá até se manter com eleições periódicas. Porém, tudo poderá ser governado por um enorme poder tutelar sobre o qual o povo terá pouco ou nenhum controle. Esse tipo de servidão regrada, doce e calma pode perfeitamente se estabelecer nas democracias. Somente com uma cultura de participação política, através de associações comunitárias, em vários níveis do poder, poderemos, diz Tocqueville, combater o despotismo crescente na democracia.
\end{abstract}

Palavras chave: Republicanismo. Tocqueville. Despotismo. Democracia.

\begin{abstract}
The aim of this article is to investigate the republicanism present in Alexis de Tocqueville as a criticism to despotism in democratic eras. For so, we will follow the interpretative reading of contemporary authors such as Hannah Arendt, Charles Taylor and Jacques Rancière, who highlight in their reflections Tocqueville's interpretation of the American Revolution, emphasizing the limits and the possibility of participatory politics as a criticism of an emerging despotism in democracy. Tocqueville observes a tendency, in democracy, for a growing modem individualism, along with the loss of community ties, which are essential for public life. He seems to be concemed with the indifference towards politics as society's participation in decisions, with the danger of a new, specifically modem, form of despotism. It will not be a tyranny of terror and oppression. The government may even hold regular elections. However, everything can be governed by an enormous tutelary power over which the people will have little or no control. This kind of sweet and calm regimented servitude can perfectly settle in democracies. Only with a culture of political participation, through community associations, at various levels of power, we shall, as stated by Tocqueville, combat the growing despotism in democracy.
\end{abstract}

Keywords: Republicanism. Tocqueville. Despotism. Democracy.

\section{Introdução}

O presente artigo investiga o republicanismo no pensamento de Alexis de Tocqueville, como crítica ao despotismo nas eras democráticas. Tal qual defende Raymond Aron, o problema de Tocqueville pode, nesse sentido, ser resumido na seguinte questão: "em que condições uma sociedade em que o destino dos indivíduos tende a ser 
uniforme pode evitar o despotismo? ${ }^{1 \%}$. Aqui, seguiremos a leitura interpretativa de autores contemporâneos como Hannalh Arendt, Charles Taylor e Jacques Rancière, que destacaram o caráter republicano presente em Tocqueville. Explicitaremos, portanto, a crítica de Tocqueville ao individualismo das sociedades modernas e o risco de as democracias desenvolverem um tipo muito específico de despotismo, que se relaciona com o desinteresse e a apatia da sociedade com a vida pública. O despotismo "retira dos homens qualquer paixão comum, qualquer necessidade mútula, qualquer obrigação de se entenderem ${ }^{2 *}$. Em suma, o despotismo enclausura os homens na vida privada.

Tocqueville utiliza-se, ao longo de suas reflexões, como veremos no decorrer deste artigo, da comparação entre as Revoluções Francesas e Americanas, como um método de análise. Ele sempre destaca possíveis semelhanças e singularidades existentes no processo de constituição da democracia, seja no contexto americano ou francês. A partir disso, Tocqueville enumera determinadas características da democracia, como sua implementação, consolidação e sua possível degeneração, haja vista a acomodação das sociedades modernas, no âmbito do individualismo extremo e da perda dos vínculos comunitários, essenciais para a vida pública. Isto, em Tocqueville, tem como consequência um desinteresse pela política, enquanto participação da sociedade nos processos decisórios, abrindo espaço para um despotismo muito peculiar dos tempos modernos, com base no cansaço da sociedade, mergulhada cada vez mais em interesses individuais, e não repulblicanos.

Como nos lembra Rainer Forst ${ }^{3}$, em Tocqueville, podemos, nesse contexto, pontuar algumas diferenças decisivas entre as Revoluções Americanas e Francesas, que residem no fato de que na França a infraestrutura aristocrática já estava absorvida pelo poder central. A Revolução Francesa teria apenas assumido e fortalecido essa tendência da aristocracia anterior ao poder revolucionário, sendo também uma revolução mais centralizadora, e menos participativa. Segundo Tocqueville" um grande número de hábitos políticos do Antigo Regime reapareceu na Revolução Francesa, como a centralização do poder.

Em contraposição, os americanos tinhham três vantagens decisivas em relação aos franceses: primeiro, sua prosperidade relativa, sem ameaça externa e sem grande população urbana empobrecida, como na França; segundo, suas leis, ou seja, a separação dos poderes, tribunais independentes, autoadministração em comunidades; e, terceiro, seus hábitos do coração, sula doutrina ética cristã e sua formação universal que, contudo, era pragmática.

Não por acaso, como veremos, Hannah Arendt, em "Sobre a revolução", refletiu profundamente as intuições de Tocqueville. Enquanto os franceses, diz Tocqueville, estavam preocupados com a revolução, os americanos, por sua vez, estavam com a democracia e com suas formas de governo. Arendt chamou isso de a "questão política", como uma preocupação essencial da Revolução Americana, enquanto que os franceses teriam se fixado apenas na chamada "questão social", sem o cuidado com as formas políticas fundamentais para uma república e uma política participativa.

As vantagens do contexto americano, segundo Tocqueville, não garantiria a democracia de não ser dominada por um tipo de despotismo muito particular dos tempos modernos, à luz de uma vida reduzida apenas ao consumismo e ao individualismo. Somente uma política voltada à participação da sociedade nos vários níveis de poder revigora a democracia, impedindo-a de ser capturada por formas despóticas, e não participativas de poder, como veremos no decorrer deste artigo.

\section{A igualdade democrática}

\footnotetext{
${ }^{1}$ ARON, Raymond. As etapas do pensamento sociológico. 7.ed. São Paulo: Martins Fontes, 2008, p.324.

${ }^{2}$ TOCQUEVILLE, Alexis de. O antigo regime e a revolução. São Paulo: Edipro, 2017, p.46.

${ }^{3}$ FORST, Rainer. Contextos da justiça: filosofia política para além de liberalismo e comunitarismo. São Paulo: Boitempo, 2010, p.146.

${ }^{4}$ TOCQUEVILLE, Alexis de. O antigo regime e a revolução. São Paullo: Edipro, 2017, p.43. 
Tocqueville, nas reflexões acerca das características da democracia, destaca a ideia da igualdade como um dos pilares essenciais das revoluções democráticas, acrescentando-se a descentralização do poder, em se tratando especificamente da Revolução Americana.

Eintre os novos objetos que me chamaram a atenção durante minha permanência nos Estados Unidos nenhum me impressionou mais do que a igualdade das condições. Descobri sem custo a influência prodigiosa que exerce esse primeiro fato sobre o andamento da sociedade; ele proporciona ao espírito público certa direção, certo aspecto às leis; aos governantes, novas máximas e hábitos particulares aos governados.

Como contextualiza Jacques Rancière ${ }^{6}$, Tocqueville entendia por "igualdade de condições" o fim das antigas sociedades divididas em ordens e castas. Não por acaso, diz Tocqueville, o poder patriarcal foi duramente abalado com o advento das democracias. A força da opinião exercida pelo pai sobre os filhos se tornou cada vez menor, "assim como seu poder legal $1^{7 \%}$. Com as revoluções democráticas, o poder da autoridade é menos absoluto, pois uma espécie de igualdade se estabelece. "A democracia derruba ou abaixa a maior parte dessas barreiras $8^{80}$.

Além disso, Tocqueville observa que, com a democracia e seu ideal de igualdade, a desigualdade entre homens e mullheres também tenderia a diminuir. A democracia também proporcionou um ganho material para um maior número de pessoas, com um significante aumento da mobilidade social, ao contrário das sociedades aristocráticas, que se caracterizavam por serem rigidamente hierarquizadas.

Contudo, Tocqueville observa uma tendência, nas democracias, de um crescente individualismo moderno, junto com a perda dos laços comunitários, essenciais para a vida púlblica. Para ele, a igualdade democrática fez com que os homens olhassem uns para os outros de uma forma cada vez mais indiferente, posto que a igualdade derrubou todas as hierarquias, como se cada indivíduo fosse agora autossuficiente.

Nossos pais não tỉnham em seu vocabulário a palavira individualismo, que forjamos para nosso uso, pois no tempo deles efetivamente não havia indivíduo que não pertencesse a um grupo e que pudesse se considerar absolutamente só ${ }^{9}$.

Os laços comunitários desfazem-se, e cada um passa a viver uma vida separada das outras. Tocqueville problematiza as consequências para a democracia de um individualismo crescente, onde a política é deixada de lado, em prol apenas de uma busca do consumismo, dos interesses privados e dos pequenos prazeres do cotidiano. Isto poderá ter consequências decisivas para a democracia e sua degeneração em direção a um despotismo de aparência democrática, como veremos a seguir.

\section{0 despotismo nas eras democráticas}

Tocqueville reflete acerca do risco de a democracia desenvolver um tipo muito específico de despotismo, denominado por ele de "despotismo doce ${ }^{10 "}$. Este degrada os

${ }^{5}$ TOCQUEVILLE, Alexis de. A democracia na américa (livro I). leis e costumes: de certas leis e certos costumes políticos que foram naturalmente sugeridos aos americanos por seu estado social democrático. 3.ed. São Paulo: Martins Fontes, 2014a, p.7.

${ }^{6}$ RANCIÈRE, Jacques. O ódio à democracia, São Paulo: Boitempo, 2014, p.31.

"TOCQUEVILLE, Alexis de. A democracia na américa (livro II): sentimentos e opiniões: de uma profusão de sentimentos e opiniões que o estado social democrático fez nascer entre os americanos. 2.ed. São Paulo: Martins Fontes, 2014b, p.239.

${ }^{8}$ TOCQUEVILLE, Alexis de. A democracia na américa (livro II): sentimentos e opiniões: de uma profusão de sentimentos e opiniões que o estado social democrático fez nascer entre os americanos. 2.ed. São Paulo: Martins Fontes, 2014b, p.241.

${ }^{9}$ TOCQUEVILLE, Alexis de. O antigo regime e a revolução. São Paulo: Edipro, 2017, p.120. 
hhomens sem os atormentar, pois se fundamenta num individualismo cada vez mais presente, bem como numa vida reduzida ao consumismo e aos pequenos prazeres cotidianos.

O despotismo, que, por natureza, é temeroso, vê no isolamento dos homens a mais segura garantia de sua duiração e, comumente, faz tudo para isolá-los. Não há vício no coração humano que lhe agrade tanto quanto o egoísmo: umm déspota perdoa facilmente aos governados não amá-lo, contanto que não se amem entre si. Não Ihes pede para ajudá-lo a conduzir o Estado; basta que não pretendam dirigi-lo. Chama de espíritos turbulentos e inquietos os que pretendem juntar esforços para criar a prosperidade comum e, alterando o sentido natural das palavras, chama de bons cidadãos os que encerram estreitamente em si mesmos ${ }^{11}$.

Charles Taylor, por exemplo, defende que, em Tocqueville, podemos observar o lado sombrio do individualismo, que torna a vida "mais pobre em significado e menos preocupada com os outros ou com a sociedade ${ }^{12 \%}$. A cultura moderna desenvolveu concepções de individualismo que retratam a pessoa humana como um ser que encontra suas coordenadas dentro apenas de si mesmo, sem nenhuma influência de outras mediações ou redes de interlocução ${ }^{13}$. Como esclarece Taylor, o indivíduo está desde sempre situado numa vivência comunitária que fornece os elementos significativos para a construção de seu self, sempre pertencente a um contexto fundamental.

Nas palavras de Taylor, "o não reconhecimento ou o reconhecimento errôneo podem causar danos, podem ser uma forma de opressão, aprisionando alguém numa modalidade de ser falsa, distorcida e redutora ${ }^{14 \%}$. Quando um bem constitutivo de uma cultura não é articulado, corre-se o risco de perder fontes morais que alimentam a vida dos sujeitos.

Tocqueville mostra-se preocupado com a indiferença pela vida pública em sujeitos cada vez mais centrados em si mesmos. Por um lado, como vimos antes, a democracia proporcionou uma maior mobilidade social; por outro, os indivíduos podem apenas viver uma vida em tomo de seus interesses pessoais e particulares. Eles preferirão ficar em casa e desfrutar as satisfações da vida privada, conquanto que o governo vigente produza os meios para tais satisfações e os distribua abertamente.

Em Tocqueville, isso expõe o perigo de uma nova, especificamente moderna, forma de despotismo. Não será uma tirania do terror e da opressão como nos tempos de outrora. O governo será moderado, podendo até manter formas democráticas, com eleições periódicas. Mas, em realidade, tudo será governado por um enorme poder tutelar sobre o qual o povo terá pouco controle.

A sociedade está tranquila, não por ter consciência de sua força e de seu bemestar, mas, ao contrário, por se acreditar fraca e enferma: ela teme morrer fazendo um esforço. Cada qual sente o mal, mas ninguém tem a coragem e a energia necessárias para buscar o melhor; tem desejos, queixas, pesares e alegrias que não produzem nada visível, nem duradouro ${ }^{15}$.

\footnotetext{
${ }^{10}$ TOCQUEVILLE, Alexis de. A democracia na américa (livro II). sentimentos e opiniões: de uma profusão de sentimentos e opiniões que o estado social democrático fez nascer entre os americanos. 2.ed. São Paulo: Martins Fontes, 2014b, p.388.

${ }_{11}$ TOCQUEVILLE, Alexis de. A democracia na américa (livro II): sentimentos e opiniões: de uma profusão de sentimentos e opiniões que o estado social democrático fez nascer entre os americanos. 2.ed. São Paulo: Martins Fontes, 2014b, p.125.

${ }^{12}$ TAYLOR, Charles. A ética da autenticidade São Paulo: Realizações Editora, 2011, p.14.

${ }^{13}$ TAYLOR, Charles. As fontes do self. a constituição da identidade moderna. 4.ed. São Paullo: Edições Loyola, 2013, p.56.

${ }^{14}$ TAYLOR, Charles. Argumentos filosóficos. São Paulo: Edições Loyola, 2000, p.241.

${ }^{15}$ TOCQUEVILLE, Alexis de. A democracia na américa (livro I): leis e costumes: de certas leis e certos costumes políticos que foram naturalmente sugeridos aos americanos por seu estado social democrático. 3.ed. São Paulo: Martins Fontes, 2014a, p.16.
} 
Tocqueville, como vimos, fala de um tipo muito específico de opressão nas democracias, não se parecendo com nada do passado. Ele diz procurar em vão por uma expressão que reproduza exatamente esse novo fenômeno típico das eras democráticas. "A coisa é nova, é preciso pois procurar defini-la, já que não posso nomeá-la16" o despotismo das sociedades democráticas, ressalta ele, faz da indiferença e do individualismo um tipo de virtude pública, fundamentando-se no desinteresse pela vida pública, em sua dimensão política.

Na democracia, haveria, portanto, o risco dos sujeitos se tornarem estranhos, indiferentes e quase invisíveis uns aos outros; o vínculo social poderá ser destruído, abrindo caminho para governos tirânicos, mas legitimados pela apatia e indiferença dos indivíduos com a vida pública. Cada homem se voltaria apenas para si mesmo, abandonando qualquer ideal de política e de vida em comum.

(...) vejo uma multidão incalculável de homens semelhantes e iguais que giram sem repouso em torno de si mesmos para conseguir pequenos e vulgares prazeres com que enchem sua alma. Cada um deles, retirado à parte, é como que alheio ao destino de todos os outros: seus filhos e seus amigos particulares formam para ele toda a espécie humana; quanto ao resto de seus concidadãos, está ao lado deles, mas não os về, toca-os mas não os sente - cada uim só existe em si mesmo e para si mesmo ${ }^{17}$.

Acima dos indivíduos, poderá ser erguido um poder imenso e tutelar, que se encarrega sozinho de assegurar o proveito da sociedade. "É absoluto, detallhado, regular, previdente e doce ${ }^{18 \%}$. Esse poder, afirma Tocqueville, traballha para a felicidade dos indivíduos, mas quer ser ele apenas o único agente de tal felicidade. Esse tipo de servidão regrada, doce e calma pode perfeitamente se estabelecer nas democracias. $O$ povo se consola, pois pensa que a própria sociedade escolhe seus tutores. "Há em nossos dias muita gente que se acomoda facilmente com essa espécie de compromisso entre o despotismo administrativo e a soberania do povo ${ }^{19 "}$.

O soberano precisaria ser vigiado de perto por uma legislatura eletiva e independente, como sugere Tocqueville, quando defende a formação das associações na democracia, instaurando um espírito participativo e comunitário na vida do povo, como veremos a seguir, tal qual uma saída para o despotismo específico das sociedades democráticas.

\section{As associações democráticas e o espírito comunal}

Tocqueville observa que, na América, a ideia das comunas se desenvolveu de modo único em relação ao contexto francês. A América se formou com a lógica de um mesmo país. Porém, seus estados possuem autonomia, com leis próprias, onde o povo participa diretamente das discussões e formulação das leis. Tocqueville enfatiza que o caráter descentralizador da Revolução Americana fez com que reinasse uma vida política real, ativa e republicana. "Na América, não apenas existem instituições comunais, mas

${ }^{16}$ TOCQUEVILLE, Alexis de. A democracia na américa (livro II): sentimentos e opiniões: de uma profusão de sentimentos e opiniões que o estado social democrático fez nascer entre os americanos. 2.ed. São Paulo: Martins Fontes, 2014b, p.389.

${ }^{17}$ TOCQUEVILLE, Alexis de. A democracia na américa (livro II): sentimentos e opiniões: de uma profusão de sentimentos e opiniões que o estado social democrático fez nascer entre os americanos. 2.ed. São Paulo: Martins Fontes, 2014b, p.389.

${ }^{18}$ TOCQUEVILLE, Alexis de. A democracia na américa (livro II): sentimentos e opiniões: de uma profusão de sentimentos e opiniões que o estado social democrático fez nascer entre os americanos. 2.ed. São Paulo: Martins Fontes, 2014b, p.389.

${ }^{19}$ TOCQUEVILLE, Alexis de. A democracia na américa (livro II): sentimentos e opiniões: de uma profusão de sentimentos e opiniões que o estado social democrático fez nascer entre os americanos. 2.ed. São Pavlo: Martins Fontes, 2014b, p.391. 
também um espírito comunal que as sustenta e vivifica ${ }^{200}$. Acontece na Europa, com frequência, afirma Tocqueville, que os próprios governantes lamentam a ausência do espírito comunal. "É na praça pública e no seio da assembleia geral dos cidadãos que se tratam, como em Atenas, os assuntos concernentes ao interesse de todos ${ }^{211 \%}$.

Jacques Rancière ${ }^{22}$ argumenta, nesse sentido, o temor que há, em Tocqueville, de um Estado centralizado que padroniza os sujeitos, gerando, ao mesmo tempo, uma massa despolitizada e apática perante a política. Já para Max Weber o Estado burocrático é o que melhor caracteriza o desenvolvimento racional do Estado moderno a partir da lógica da racionalização e do desencantamento do mundo. Weber nota, pela primeira vez, o aparecimento, na modernidade, de "políticos profissionais ${ }^{23 "}$. Ou seja, fazer política não é algo mais relacionado à ideia de uma comunidade, polis ou de uma vida pública, e sim ter uma profissão no âmbito de um Estado centralizado e burocrático. O mesmo diz Hannah Arendt, quando afirma que a "política passou a ser uma profissão e uma carreira, e portanto a "elite" tem sido escolhida de acordo com padrões e critérios que são, em si mesmos, profundamente apolíticos ${ }^{24 \%}$.

Em Tocqueville, faz-se necessário, portanto, um reestabelecimento dos vínculos como uma forma de revitalizar a democracia, através da criação das associações, tal qual um oxigênio para a vida pública. "Os sentimentos e as ideias só se renovam, o coração só aumenta e o espírito humano só se desenvolve mediante a ação recíproca dos homens uns sobre os outros ${ }^{25 \%}$. Não se trata de uma volta romântica ao passado pré-moderno, e sim de construirmos associações como uma recriação e ressignificação dos vínculos. " $E$ isso somente as associações podem fazer ${ }^{26 "}$. É preciso, por isso, que as associações se desenvolvam e se aperfeiçoem sempre, no sentido de uma instância onde a sociedade possa participar das deliberações.

Dessa maneira, a vida comunal se faz, de certa forma, sentir a cada instante; ela se manifesta cada dia pelo cumprimento de um dever ou pelo exercício de um direito. Essa existência política imprime à sociedade um movimento contínuo, mas ao mesmo tempo tranquilo, que a agita sem perturbá-la ${ }^{27}$.

A única defesa contra os despotismos das sociedades democráticas é, segundo Tocqueville, uma vigorosa cultura política na qual a participação é valorizada. Diante disso, Taylor nos explica que:

Muitos pensadores contemporâneos viram a obra de Tocqueville como profética. Se é assim, o que corremos o risco de perder é o controle político sobre nosso destino, algo que poderíamos exercer em comum como cidadãos. É isso que Tocqueville chama de "liberdade política". O que está ameaçada aqui é a nossa dignidade como cidadãos ${ }^{28}$.

${ }^{20}$ TOCQUEVILLE, Alexis de. A democracia na américa (livro I): leis e costumes: de certas leis e certos costumes políticos que foram naturalmente sugeridos aos americanos por seu estado social democrático. 3.ed. São Paulo: Martins Fontes, 2014a, p.78.

${ }^{21}$ TOCQUEVILLE, Alexis de. A democracia na américa (livro I): leis e costumes: de certas leis e certos costumes políticos que foram naturalmente sugeridos aos americanos por seu estado social democrático. 3.ed. São Paulo: Martins Fontes, 2014a, p.48-9.

${ }^{22}$ RANCIËRE, Jacques. O ódio à democracia. São Paulo: Boitempo, 2014, p.32.

${ }^{23}$ WEBER, Max. Ciência e política: duas vocações. 18.ed. São Paulo: Editora Cultrix, 2011, p.75.

${ }^{24}$ ARENDT, Hannah. Sobre a revolução. São Paulo: Companhia das Letras, 2011, p.347.

${ }^{25}$ TOCQUEVILLE, Alexis de. A democracia na américa (livro II). sentimentos e opiniões: de uma profusão de sentimentos e opiniões que o estado social democrático fez nascer entre os americanos. 2.ed. São Paulo: Martins Fontes, 2014b, p.134.

${ }^{26}$ TOCQUEVILLE, Alexis de. A democracia na américa (livro II); sentimentos e opiniões: de uma profusão de sentimentos e opiniões que o estado social democrático fez nascer entre os americanos. 2.ed. São Paullo: Martins Fontes, 2014b, p.134.

${ }^{27}$ TOCQUEVILLE, Alexis de. A democracia na américa (livro I): leis e costumes: de certas leis e certos costumes políticos que foram naturalmente sugeridos aos americanos por seu estado social democrático. 3.ed. São Paulo: Martins Fontes, 2014a, p.79.

${ }^{28}$ TAYLOR, Charles. A ética da autenticidade São Paulo: Realizacões Editora, 2011, p.19. 
Tocqueville fala, por conseguinte, da relação entre as associações e os jornais. Estes seriam como espaços de encontro entre os sujeitos, funcionando como uma esfera de combate ao individualismo, florescendo, ao mesmo tempo, o espírito público e republicano da participação do povo nas discussões da sociedade. Para Tocqueville, os homens podem desejar se encontrar, mas ao mesmo tempo se sentem perdidos na multidão. Eles não se veem e não sabem onde se encontrar. Surgem assim os jornais.

Seria reduzir sua importância crer que só servem para garantir a liberdade; eles mantêm a civilização. (...) Não negarei quie, nos povos deinocráticos, os jornais muitas vezes levam os cidadãos a tomar em comum iniciativas insensatas; mas, se não houvesse jomais, quase não haveria ação comum. 0 mal que eles produzem é, portanto, bem menor do que o mal que curam ${ }^{29}$.

Os homens precisavam encontrar um meio de se falar todos os dias sem se ver e de caminhar sem se juntar. Assim, diz Tocqueville, não há associação democrática que possa prescindir de um jornal. Ele afirma que há uma relação necessária entre as associações e os jornais: os jornais fazem as associações e as associações os jornais. As associações devem aumentar à medida também que os jornais se multiplicam, havendo, como explicitamos antes, uma relação interdependente entre associações, democracia e jornais, desde que haja a garantia da pluralidade dos espaços de discussão, evitando a concentração de poder. "Por isso, a América é o país do mundo em que existem, ao mesmo tempo, mais associações e mais jornais $3^{30 "}$.

Não à toa Tocqueville afirma que o acréscimo ou a diminuição dos jornais é proporcional à diminuição da centralização do poder ou de seu aumento. Quanto maior os vínculos entre os sujeitos e as associações, maior a proliferação de jornais, bem como mais plural e participativa seria a democracia. Os jornais não se multiplicam apenas por causa do menor preço, mas pela necessidade de um grande número de homens de se comunicar, discutir e agir em comum. Um jornal só pode subsistir se reproduzir uma doutrina ou um sentimento comum a um grande número de homens. Um jornal sempre representa, portanto, uma associação a que seus leitores habituais são afiliados ${ }^{31}$.

Essa liberdade comunicativa, defendida por Tocqueville, influenciou diretamente Hannalh Arendt que, em diálogo com a obra do autor de "A Democracia na América", destaca que, na Revolução Americana, a palavra "povo", por exemplo, conservava o significado de multiplicidade, de variedade infindável de uma multidão cuja grandeza residia em sua própria pluralidade. Segundo Rainer Forst ${ }^{32}$, o livro "Sobre a Revolução", de Arendt, é, em suas proposições centrais, uma recepção do contraste tocquevilleano entre as Revoluções Americana e Francesa, pois Tocqueville viu a importância que as associações civis teriam para a renovação do poder nas democracias, no que diz respeito à participação da sociedade civil nos rumos da política.

Arendt, por conseguinte, defende a importância dos conselhos na democracia, como uma esfera onde o povo, em seu sentido múltiplo e diversificado, possa também participar do poder. Os conselhos apontariam para uma democracia descentralizada e participativa.

\footnotetext{
${ }^{29}$ TOCQUEVILLE, Alexis de. A democracia na américa (livro II); sentimentos e opiniōes: de uma profusão de sentimentos e opiniões que o estado social democrático fez nascer entre os americanos. 2.ed. São Paulo: Martins Fontes, 2014b, p.137.

${ }^{30}$ TOCQUEVILLE, Alexis de. A democracia na américa (livro II): sentimentos e opiniões: de uma profusão de sentimentos e opiniões que o estado social democrático fez nascer entre os americanos. 2.ed. São Paulo: Martins Fontes, 2014b, p.138.

${ }^{31}$ TOCQUEVILLE, Alexis de. A democracia na américa (livro II); sentimentos e opiniões: de uma profusão de sentimentos e opiniões que o estado social democrático fez nascer entre os americanos. 2.ed. São Paulo: Martins Fontes, 2014b, p.140.

${ }^{32}$ FORST, Rainer. Contextos da justiça filosofia política para além de liberalismo e comunitarismo. São Paulo: Boitempo, 2010, p.146.
} 
(...) Jefferson ao menos pressentiu como seria perigoso permitir ao povo uma participação no poder público sem fornecer ao mesmo tempo um espaço público maior do que a urna eleitoral e uma oportunidade mais ampla de expressar suas opiniões em público, que não se resumisse ao dia das eleições. O que ele viu como uim perigo mortal para a república foi que a Constituição dera todo o poder aos cidadãos sem lhes dar a oportunidade de ser republicanos e de agir como cidadãos. Em outras palavras, o perigo era que todo o poder fora dado ao povo em sua qualidade privada e não se estabelecera um espaço para o povo em sua qualidade de cidadania ${ }^{33}$

Arendt enfatiza que, na Revolução Americana, ao contrário da Francesa, havia um destaque para as questões políticas, e não apenas as sociais. O problema apenas de se destacar a questão social, e não a política, como na Revolução Francesa, é que, depois de assegurada a sobrevivência dos pobres, suas vidas continuam a não ter influência, sendo excluídas da esfera pública e das decisões políticas: "eles permanecem nas sombras, aonde quer que possam $\operatorname{ir}^{34}$. A democracia não poderia ser apenas um exercício dos partidos políticos, e nem ser uma prática apenas no dia da eleição, mas, sobretudo, deve ser articulada no âmbito da participação da sociedade nos rumos do poder.

A política, diz Arendt, não é apenas representação, e sim, essencialmente, participação. Nas palavras de Arendt, "a esfera pública numa república era constituída pela troca de opiniões entre iguais, e que essa esfera simplesmente desapareceria no instante em que essa troca se tornasse supérflua ${ }^{35 "}$. Além disso, "aos olhos dos homens da Revolução Americana, o domínio da opinião pública era uma forma de tirania ${ }^{36 " \text {, }}$ como também enfatizou Tocqueville, ao relatar o risco do despotismo nas eras democráticas, como vimos ao longo deste artigo.

\section{Referências}

ARENDT, Hannalh. Sobre a revolução. São Paulo: Companhia das Letras, 2011.

ARON, Raymond. As etapas do pensamento sociológico. 7.ed. São Paulo: Martins Fontes, 2008.

FORST, Rainer. Contextos da justiça: filosofia política para além de liberalismo e comunitarismo. São Paulo: Boitempo, 2010.

RANCIÈRE, Jacques. O ódio à democracia. São Paulo: Boitempo, 2014.

TAYLOR, Charles. Argumentos filosóficos. São Paulo: Edições Loyola, 2000.

TAYLOR, Charles. A ética da autenticidade. São Paulo: Realizações Editora, 2011.

TAYLOR, Charles. As fontes do self. a constituição da identidade moderna. 4.ed. São Paulo: Edições Loyola, 2013.

TOCQUEVILLE, Alexis de. A democracia na américa (livro I): leis e costumes: de certas leis e certos costumes políticos que foram naturalmente sugeridos aos americanos por seu estado social democrático. 3.ed. São Paulo: Martins Fontes, 2014a.

TOCQUEVILLE, Alexis de. A democracia na américa (livro II): sentimentos e opiniões: de uma profusão de sentimentos e opiniões que o estado social democrático fez nascer entre os americanos. 2.ed. São Paulo: Martins Fontes, 2014b.

${ }^{33}$ ARENDT, Hannah. Sobre a revolução. São Paulo: Companhia das Letras, 2011, p.318.

${ }^{34}$ ARENDT, Hannah. Sobre a revolucão. São Paulo: Companhia das Letras, 2011, p.104.

${ }^{35}$ ARENDT, Hannah. Sobre a revolução. São Paulo: Companhia das Letras, 2011, p.132-3.

${ }^{36}$ ARENDT, Hannah. Sobre a revolução. São Paulo: Companhia das Letras, 2011, p.133. 
TOCQUEVILLE, Alexis de. O antigo regime e a revolução: São Paulo: Edipro, 2017.

WEBER, Max. Ciência e política: duas vocações. 18.ed. São Paulo: Editora Cultrix, 2011.

Doutor em Filosofia (UFC, 2017)

Pós-Doutorando em Filosofia (UFPI/PNPD)

Email: julianopesquisa81@gmail.com 